\title{
Treatment planning for children with attention-deficit/hyperactivity disorder: treatment utilization and family preferences
}

This article was published in the following Dove Press journal:

Patient Preference and Adherence

14 January 2011

Number of times this article has been viewed

\author{
William B Brinkman \\ Jeffery $N$ Epstein \\ Department of Pediatrics, Cincinnati \\ Children's Hospital Medical Center, \\ University of Cincinnati College \\ of Medicine, Cincinnati, OH, USA
}

Background: Attention-deficit/hyperactivity disorder (ADHD) is a common condition that often results in child and family functional impairments. Although there are evidence-based treatment modalities available, implementation of and persistence with treatment plans vary with patients. Family preferences also vary and may contribute to variability in treatment utilization.

Objective: The objective of this study is to describe the evidence-based treatments available for ADHD, identify patterns of use for each modality, and examine patient and parent treatment preferences.

Method: Literature review.

Results: Treatment options differ on benefits and risks/costs. Therefore, treatment decisions are preference sensitive and depend on how an informed patient/parent values the tradeoffs between options. Literature on patient and parent ADHD treatment preferences is based on quantitative research assessing the construct of treatment acceptability and qualitative and quantitative research that assesses preferences from a broader perspective. After a child is diagnosed with $\mathrm{ADHD}$, a variety of factors influence the initial selection of treatment modalities that are utilized. Initial parent and child preferences are shaped by their beliefs about the nature of the child's problems and by information (and misinformation) received from a variety of sources, including social networks, the media, and health care providers. Subsequently, preferences become further informed by personal experience with various treatment modalities. Over time, treatment plans are revisited and revised as families work with their health care team to establish a treatment plan that helps their child achieve goals while minimizing harms and costs.

Conclusions: Studies have not been able to determine the extent to which utilization rates are consistent with the underlying distribution of informed patient/parent treatment preferences. There are challenges to ensure that patient/parent preferences are consistently well informed, elicited, and discussed in the treatment planning process. Interventions are needed to promote such interactions.

Keywords: attention-deficit/hyperactivity disorder, ADHD, adherence, preferences, physicianpatient/parent communication, collaborative/shared decision making

\section{Introduction}

Attention-deficit/hyperactivity disorder (ADHD) is a neurobehavioral condition that often results in academic, social, and family functional impairments. ADHD is prevalent, as $8.7 \%$ of children aged 8-15 years in the US meet diagnostic criteria for ADHD. ${ }^{1}$ Fortunately, there are evidence-based treatment modalities available. However, implementation of and persistence with treatment plans vary with patients. Family preferences contribute to variability in treatment implementation and adherence to treatment. Further, familial preferences appear to vary across treatment modalities. 
The purpose of this review is to describe the evidence-based treatments available for ADHD, identify patterns of use for each modality, and examine patient and parent treatment preferences. This synthesis of information will hopefully inform future research in order to better understand the relationship between preferences and treatment utilization as well as interventions to improve treatment planning for children with ADHD.

\section{Study identification}

Studies included in this review were found in the MedLine and PsychInfo databases by crossing the terms "attention deficit hyperactivity disorder", "attention deficit disorder", and "ADHD” with key terms, including "preferences", "adherence", "treatment", "management", "guideline", "primary care", and "communication". Among included articles, a secondary review of cited references was performed.

\section{Evidence-based ADHD treatment options}

The Multimodal Treatment Study of Children with ADHD (MTA $)^{2}$ provides evidence to support the use of 1) psychosocial treatments alone, 2) medication alone, or 3) combined treatment (eg, both psychosocial and medication treatments). In this review we describe each treatment modality; provide an estimate for the likelihood of benefit; identify possible shortcomings, including possible harms, costs, and barriers to implementation; and provide estimates for the use of and persistence with each modality. We limit our discussion to treatment modalities employed in the MTA study because these are the only modalities endorsed in prominent ADHD treatment guidelines. ${ }^{3,4}$ Although additional treatment modalities are increasingly being used ${ }^{5-7}$ and tested, ${ }^{8}$ none is endorsed in the current treatment guidelines. . $^{3,4}$

\section{Psychosocial treatments}

Psychosocial approaches to treatment can cover a range of specific interventions, but most of the existing evidence-based interventions support two primary components: direct contingency management and clinical behavior therapy. Direct contingency management focuses on direct control of consequences for target behavior. Clinical behavior therapy involves teaching parents and/or teachers to implement strategies for managing ADHD in everyday settings. The MTA study included both components of psychosocial intervention as part of its psychosocial treatment strategy. Families participated in parent training groups, a school-based intervention, and a summer treatment program. ${ }^{2}$ The parent training groups involved 27 group (six families/group) and eight individual sessions. Training focused on teaching parents strategies (eg, giving effective commands, setting gradual goals, and using reward systems) to encourage desired behaviors and eliminate problem behaviors. The school-based intervention involved teachers learning classroom behavior management strategies during 10-16 training sessions and paraprofessional aides working one on one with children for half the school day for up to 60 days to improve classroom behaviors. A teacher-completed daily report card was used to communicate child performance to parents, who reinforced behavior with home-based rewards. Finally, children attended a summer treatment program $9 \mathrm{~h}$ a day, 5 days/week, for 8 weeks. Summer treatment program psychosocial interventions were group based and delivered in recreational and classroom settings to improve social skills and classroom behaviors.

At the end of the 14-month MTA study, 34\% of children who received these intensive psychosocial treatments (without any medication) improved to the point of ADHD symptom remission (ie, they were no more inattentive, hyperactive, or impulsive than the average child their age without ADHD). ${ }^{9}$ No child or parent in the MTA study reported harm from the psychosocial interventions. However, there are potential shortcomings from these treatments. Obviously, parents and children need to invest time and effort into developing new skills for these approaches to be successful. In addition, there is an out-of-pocket cost to families interested in receiving these interventions in clinical settings. Moreover, the availability of interventions similar to those employed in the MTA study may be limited or nonexistent in some areas. Psychosocial treatments that are available likely vary in intensity and their adherence to evidence-based intervention programs.

In the MTA study, the parents of only 1 of 289 children randomly assigned to receive psychosocial treatment (in psychosocial treatment alone and combined treatment groups) refused to initiate psychosocial treatment. ${ }^{2}$ Of those who participated in the intervention, attendance at treatment sessions was high. Families attended an average of $77.8 \%$ of parent training sessions and $91 \%$ of possible summer treatment program days. ${ }^{2}$ However, the MTA study did not measure whether parents actually implemented psychosocial treatments as intended. Although parents who failed to attend sessions could not learn the parenting skills taught, being present at sessions did not ensure that parents either learned or implemented the parenting skills taught. ${ }^{10}$ Efforts to disseminate parent training sessions in community settings highlight potential challenges related to session attendance. Barkley et $\mathrm{al}^{11}$ offered manualized and well-validated parent 
training groups ( 10 sessions followed by 4 booster sessions) to parents of disruptive preschool age children. Thirty-three percent of parents did not attend any session, $25 \%$ of parents attended 1-4 sessions, 29\% attended 5-8 sessions, and 13\% attended 9-14 sessions. ${ }^{11}$ The authors speculate that poor attendance contributed to the intervention's lack of benefit. Despite its potential importance as a mediator of treatment outcome, attendance is under-reported in studies of psychosocial treatment among parents of children with ADHD. ${ }^{10}$ In addition, there are few estimates of utilization of psychosocial treatments. Among children with ADHD in North Florida, USA, in 1995, 25\% received multimodal treatment that included psychosocial treatments. ${ }^{12}$ We are not aware of any such estimates among a nationally representative sample.

\section{Medication}

The most widely evaluated approach to treating ADHD has been the use of different types of medications, particularly stimulant medications. The MTA medication algorithm started with a 28-day, double-blind, daily-switch titration of methylphenidate hydrochloride at a range of dosages to determine the best starting dosage. ${ }^{13}$ Similar to previous research, $77 \%$ of children in the MTA group had a positive response to methylphenidate. ${ }^{14}$ Among those children who did not, about half had a positive response to a trial of dextroamphetamine. ${ }^{14}$ Subsequently, children had monthly visits with a pharmacotherapist to monitor benefit and side effects and adjust dosage and/or medication to optimize response. Adjustment decisions were based on information obtained from children, parents, and teachers on a monthly basis. By the end of 14 months of medication treatment, only $29 \%$ of children remained on the original medication dosage. ${ }^{15}$ The average number of adjustments was two per child. ${ }^{15}$

Fifty-six percent of children who received the MTA medication algorithm (without any psychosocial treatment) improved to the point of ADHD symptom remission by the end of the 14-month study. ${ }^{9}$ Side effects from medication were common, with $50 \%$ of children reporting mild, $11 \%$ moderate, and $3 \%$ severe side effects at some time during the 14 months of treatment. ${ }^{2}$ In clinical settings, families often incur an out-of-pocket cost to obtain medication. In addition, medication management obtained in primary care settings likely differs from MTA procedures with regard to initial titration (eg, open-label upward titration rather than a blinded, placebo-controlled trial) and frequency of monitoring after the child is stable (eg, every 3-6 months rather than monthly). ${ }^{3}$ In addition, there are often logistical barriers to obtaining feedback from teachers to inform medication management decisions. ${ }^{16}$

In the MTA study, the parents of 18 of 289 children (6.2\%) randomly assigned to receive medication (in medication alone and combined treatment groups) refused to initiate medication, and an additional 20 parents $(6.9 \%)$ discontinued medication some time after their child's initial titration was complete. ${ }^{2}$ Despite coordinated research efforts to optimize adherence (eg, pill counts, intermittent saliva measurement to monitor methylphenidate taking, and encouragement of families to reschedule missed visits), ${ }^{2}$ medication use varied considerably among children in the MTA study. Just over half of children $(136 / 254=53.5 \%)$ had detectable levels of methylphenidate every time a readable saliva measurement was obtained during the 14-month study. ${ }^{17}$ Medication adherence was a significant mediator of symptom reduction in the MTA study. ${ }^{13}$ Since the MTA study was published in 1999 there have been few estimates of ADHD medication use in community-based clinical samples. One such study, which included a sample representative of the US population in 2000-2002, reported that Caucasian children were more than twice as likely to have received treatment for ADHD (5.8\%) than AfricanAmerican (2.8\%) or Hispanic (2.4\%) children. ${ }^{18}$ Another study employed a sample representative of the US population in 2003 and found that only $56.3 \%$ of children with reported ADHD diagnosis were being treated with medication at the time of the survey. ${ }^{19}$ Medication treatment rates for children diagnosed with ADHD varied widely by state, with a range from $40.6 \%$ in California to $68.5 \%$ in Nebraska. ${ }^{19}$ Analysis of California Medicaid claims (2000-2003) demonstrated that $30 \%$ of children experience a 30 -day gap in ADHD medication supply after receiving their initial prescription. ${ }^{20}$ The average time from initiation of ADHD medication to experiencing a 30 -day gap in treatment was $<150$ days..$^{20}$ Less than half of these children resumed ADHD treatment within 90 days after experiencing a gap in medication supply. ${ }^{20}$ Among Medicaid recipients in California ${ }^{20}$ and Texas, ${ }^{21}$ use of extended-release ADHD medications, compared with immediate-release medications, predicted greater persistence with medication. In a study of children with ADHD cared for in Kaiser Permanente of Northern California, a nonprofit integrated health care delivery system, medication copayment amount was found to be inversely related to duration of medication treatment (ie, lower out-of-pocket expense for filling a prescription related to longer persistence with medication treatment). ${ }^{22}$ The current literature on changes in ADHD medication use over time is limited by reliance on large pharmacy and/ or claims databases that lack linkage to the child's clinical 
treatment plan. Thus, it is impossible to know the proportion of children who discontinue medication use because they are able to achieve their goals for treatment without medication versus those who continue to struggle and discontinue medication for other reasons.

\section{Combined treatment}

Combined treatment involves receipt of both the psychosocial and medication treatments described above. At the end of the 14-month MTA study, $68 \%$ of children who received combined treatment improved to the point of symptom remission. ${ }^{9}$ In addition, children who received combined treatment ended the 14-month study on a lower dose (18\% less medication per day) than those in the medication only group. ${ }^{15}$ This is noteworthy because side effects, when present, can become more severe as dosages increase. ${ }^{14}$ The shortcomings of each modality involved in combined treatment are listed in this review within the description of each treatment option. The cumulative effect of shortcomings, such as out-of-pocket cost, may weigh significantly in the treatment planning process for families with limited resources. Utilization of these modalities is described previously.

\section{ADHD treatment planning: a series of preference-sensitive decisions}

The MTA study demonstrated the comparative efficacy of psychosocial treatment alone, medication treatment alone, and combined treatment. As reviewed previously, the chance of symptom remission and potential shortcomings (eg, harms and costs) vary across these treatment conditions. As a result, ADHD treatment guidelines recognize all three options as medically reasonable. ${ }^{3,4}$ These guidelines stress the importance of taking into account family goals, preferences, cultural values, and concerns when developing a treatment plan.,
The best initial treatment choice for the individual child depends on how an informed patient and parent(s) value the benefits relative to the potential harms/costs, as well as their ability to implement each option. Such decisions have been described as preference sensitive. ${ }^{23}$ As families accrue experience with one or more treatment modalities and recognize the actual benefits and harms/cost experienced by their child, the best treatment plan becomes one that strikes an acceptable balance between enabling progress toward current and future child/family goals while minimizing any harms/costs.

\section{Patient and caregiver preferences}

Our current understanding of patient and parent ADHD treatment preferences is based on quantitative research that assesses the construct of treatment acceptability and qualitative and quantitative research that assesses preferences from a broader perspective. Each method contributes to the literature on what matters most to patients and parents when selecting ADHD treatments. In this review we highlight the key findings, limitations, and unanswered questions.

\section{Treatment acceptability}

Studies of treatment acceptability among parents of children with ADHD are reviewed here. These studies have employed a variety of measures: 1) Treatment Evaluation Inventory (TEI), ${ }^{24-26}$ 2) Modified TEI, ${ }^{27} 3$ ) Adapted TEI Short Form, ${ }^{28}$ 4) Treatment Acceptability Questionnaire (TAQ), $\left.{ }^{29} 5\right)$ ADHD Knowledge and Opinion Scale (AKOS), ${ }^{30}$ 6) Modified AKOS, ${ }^{31}$ and 7) AKOS-Revised (AKOS-R). ${ }^{32}$ The commonalities and differences between these scales with regard to the measurement of the "acceptability" construct are summarized in Table 1. All scales ask respondents to rate their agreement with a series of statements, and all generate a total score, with higher scores indicating greater acceptability. Unlike

Table I Comparison of acceptability measures

\begin{tabular}{|c|c|c|c|c|c|c|}
\hline \multirow[t]{2}{*}{ Measure } & \multicolumn{6}{|c|}{ Item content } \\
\hline & $\begin{array}{l}\text { Treatment } \\
\text { acceptable }\end{array}$ & $\begin{array}{l}\text { Benefit } \\
\text { expected }\end{array}$ & $\begin{array}{l}\text { Treatment } \\
\text { appropriate }\end{array}$ & $\begin{array}{l}\text { Treatment } \\
\text { liked }\end{array}$ & $\begin{array}{l}\text { Willing } \\
\text { to use }\end{array}$ & $\begin{array}{l}\text { Devoid of } \\
\text { bad side effects }\end{array}$ \\
\hline $\begin{array}{l}\text { TEl (Kazdin, }{ }^{24} \text { Liu et al, }{ }^{25} \text { and } \\
\text { Gage and Wilson }{ }^{26} \text { ) }\end{array}$ & $\mathrm{X}$ & $\mathrm{x}$ & $\mathrm{X}$ & $\mathrm{X}$ & $\mathrm{X}$ & \\
\hline Modified TEI (Johnston and Fine ${ }^{27}$ ) & $X$ & $x$ & $X$ & $X$ & $X$ & \\
\hline $\begin{array}{l}\text { Adapted TEl Short Form } \\
\text { (Johnston et } \mathrm{al}^{28} \text { ) }\end{array}$ & $X$ & & & & $X$ & \\
\hline $\begin{array}{l}\text { Treatment Acceptability Questionnaire } \\
\left(\text { Krain et } \mathrm{al}^{29}\right)\end{array}$ & $\mathrm{X}$ & $\mathrm{X}$ & $\mathrm{X}$ & $\mathrm{X}$ & & $x$ \\
\hline AKOS (Rostain et $\mathrm{al}^{30}$ ) & $\mathrm{X}$ & $x$ & & & $X$ & $x$ \\
\hline Modified AKOS (Corkum et $\mathrm{al}^{31}$ ) & $\mathrm{x}$ & $x$ & & & $X$ & $\mathrm{X}$ \\
\hline AKOS-R (Bennett et $\mathrm{al}^{32}$ ) & $\mathrm{X}$ & $\mathrm{X}$ & & & $X$ & $\mathrm{X}$ \\
\hline
\end{tabular}

Abbreviations: TEl, Treatment Evaluation Inventory; AKOS, ADHD Knowledge and Opinion Scale; AKOS-R, ADHD Knowledge and Opinion Scale-Revised. 
versions of the TEI and TAQ, which have a single scale that can be completed in reference to various treatment options/ modalities, versions of the AKOS have separate scales that are specific for medication acceptability, psychosocial treatment acceptability, and psychosocial treatment feasibility.

\section{Relative acceptability of ADHD treatment modalities}

At the time of diagnosis, parents ${ }^{25,29}$ and children ${ }^{25}$ view psychosocial treatment as a more acceptable option than medication. One study found that ADHD knowledge at the time of diagnosis was positively correlated with acceptability of psychosocial treatment but not medication. ${ }^{31}$ Another study found that medication acceptability at the time of diagnosis was significantly higher among Caucasian parents compared with non-Caucasian parents (25\% of sample). ${ }^{29}$ Actual experience with medication can increase parent-reported acceptability of medication treatment for ADHD. ${ }^{25,27}$ Interestingly, increased acceptability of medication after the initial medication trial was related to increased parent knowledge of ADHD and ADHD treatment modalities ${ }^{25}$ and not to the degree of child symptom reduction. ${ }^{25,27}$ With experience, some parents may come to find combination treatment most acceptable. ${ }^{25,26}$

\section{Acceptability of psychosocial treatments among experienced parents}

Among parents with past experience with psychosocial treatments, views of effectiveness were positively correlated with acceptability of psychosocial treatments in one study ${ }^{28}$ and were unrelated in another study. ${ }^{32}$ One study found that psychosocial treatment acceptability (but not psychosocial treatment feasibility) was higher among mothers than among fathers. ${ }^{32}$ The same study found that psychosocial treatment acceptability for both mothers and fathers was positively correlated with children's externalizing problems. ${ }^{32}$ Psychosocial treatment acceptability was also higher among mothers who knew an acquaintance with ADHD than among those who did not. ${ }^{32}$ One study found that parent acceptability of psychosocial treatments decreased after participating for 12 months in either parent training or support groups. ${ }^{31}$ It is not clear whether this was due to perceived lack of effectiveness or other factors. Another study found that ADHD knowledge among fathers was positively correlated with past participation in psychosocial treatments. ${ }^{30}$

No study found psychosocial treatment acceptability to be related to initiation (attending at least one session) of recommended psychosocial treatment ${ }^{29,31,32}$ or the number of sessions attended. ${ }^{32}$ It is noteworthy that there was limited variability in the high ratings of psychosocial treatment acceptability in two of the three studies that examined this relationship. ${ }^{29,31}$ One study found that ADHD knowledge predicted attending at least one parent training or support group. ${ }^{31}$

\section{Acceptability of medication treatments among experienced parents}

Among parents with past experience with medication treatment, views of effectiveness were not related to medication acceptability in one study ${ }^{28}$ but were positively correlated with medication acceptability among mothers (but not fathers) in another study. ${ }^{32}$ Among mothers, ADHD knowledge was negatively correlated with medication acceptability in one study ${ }^{30}$ but positively correlated with medication acceptability for both mothers and fathers in another study. ${ }^{32}$ One study found no significant difference between mothers and fathers on medication acceptability. ${ }^{32}$ Side effect ratings were negatively correlated with medication acceptability among mothers but not fathers. ${ }^{32}$

Research on the relationship between acceptability and medication adherence has mixed findings. One study found that medication acceptability and ADHD knowledge predicted implementing the recommendation to initiate a trial of medication (eg, taking at least one methylphenidate or placebo pill), ${ }^{31}$ but another study found no such relationship. ${ }^{32}$ Krain et $\mathrm{al}^{29}$ found that significantly more Caucasian children than non-Caucasian children (79\% vs $27 \%$ ) initiated medication (eg, ingestion of at least one pill) during the follow-up period (eg, average 3.7 months). After controlling for race, acceptability ratings significantly predicted initiation of medication. ${ }^{29}$ Johnston and Fine ${ }^{27}$ reported that following a medication titration, medication adherence (ie, composite score comprising missed pills; missed appointments; saliva methylphenidate; and parent-, teacher-, and physician-reported compliance) over 3 months of treatment was not related to acceptability scores (either before or after the initial trial of medication), consumer satisfaction, treatment response, or recommended dosage. Likewise, Corkum et $\mathrm{al}^{31}$ found no relationship between acceptability and adherence. In this study, the adherent category was defined by taking $\geq 50 \%$ of pills based on pill count. Based on this definition, 36/68 (53\%) adhered to treatment, with those randomized to medication being more adherent than those randomized to placebo $(25 / 35=74 \%$ vs $11 / 34=32 \%$ ). By 12 months, parent knowledge of ADHD 
increased significantly, but ADHD knowledge was not related to adherence.

\section{Limitations of acceptability research}

Acceptability research among parents of children with ADHD has several limitations. First, studies employ different measures of acceptability and include samples that vary considerably with regard to their past experience with ADHD treatment modalities. These factors make it challenging to interpret contradictory findings across studies. Second, only two of the eight studies reviewed assessed the relative acceptability of combined treatment (eg, both psychosocial and medication treatment). ${ }^{25,26}$ This appears to be an important distinction, as combined treatment may be viewed more favorably than either treatment in isolation. ${ }^{26}$ Third, the child's perspective on acceptability is almost completely neglected. Only one study collected these responses from children at diagnosis, ${ }^{25}$ and no attempt was made to ascertain whether the child's view of acceptability changed after trying treatment. Likewise, few studies examined how the views of fathers ${ }^{30,32}$ and minorities ${ }^{29}$ might differ. Fourth, there are few longitudinal studies that assess change in acceptability over time, ${ }^{25,27,31}$ and these studies are limited by attrition (eg, only 27/50 completed follow-up, with those initiating medication more likely to complete surveys $)^{25}$ and selection bias (eg, sample included only those willing to try medication ${ }^{27}$ or willing to be randomized to a 12-month treatment trial). ${ }^{31}$ Finally, analyses related to prediction of medication adherence may be confounded by the inclusion of children receiving a placebo. ${ }^{31}$ Adherence was extremely poor in the placebo group and may reflect discontinuation due to lack of effectiveness. ${ }^{31}$

\section{Summary of acceptability studies}

It seems clear that psychosocial treatments are generally more acceptable to parents than medication initially and that acceptability can change over time as parents garner valuable experience of managing ADHD with a variety of treatment modalities. However, acceptability alone has not been shown to predict implementation of psychosocial treatment, which is likely influenced by a variety of factors, such as service availability and feasibility of family attendance (eg, time and affordability). Likewise, the relationship between acceptability and medication initiation appears inconsistent. Continuing medication after a titration trial is likely related to a variety of factors (ie, perceived need, perceived benefit, perceived side effects/concerns, patient acceptance, social support, and cost), of which acceptability is just one. Therefore, the construct of "acceptability" appears to have limited explanatory value in understanding child and caregiver ADHD treatment preferences. As such, we look to other bodies of literature for additional insights.

\section{Qualitative and quantitative research assessing treatment preferences}

Qualitative research methods are another way to better understand child and parent preferences about ADHD treatment. By allowing themes to emerge, rather than limiting inquiry to predefined constructs expected to explain a phenomenon, qualitative studies have enabled parents and children with ADHD to identify aspects of treatment that are important to them, using their own words. In addition, quantitative research that has built on these qualitative research studies has contributed important insights by exploring a variety of constructs identified by parents and children. This literature, which is reviewed below, spans the long and winding road traveled by families from the onset of child problem behaviors to entering the medical system, receiving a diagnosis, negotiating the initial treatment plan, and subsequently revisiting and revising the treatment plan. Collectively, this literature illustrates that treatment preferences are often dynamic, informed by real-world experience with a variety of ADHD treatments, and context dependent as family goals/priorities evolve and progress toward these target outcomes is appraised.

\section{Parent treatment preferences}

The initial decision to seek medical help for ADHD symptoms is influenced by a parent's explanatory model of ADHD (eg, parental beliefs about etiology, expected time course, severity, parental worries, preferred treatments, and desired treatment outcomes). One study examined such beliefs among parents of children "at risk" for ADHD who subsequently met diagnostic criteria for ADHD based on parent reports on the Diagnostic Interview Schedule for Children Version IV. ${ }^{33}$ In this study, parents of untreated children, compared with parents of children who had received psychosocial and/or medication treatment for ADHD in the past year, were less likely to 1) believe that ADHD would have a long time course, 2) voice concern about their child having a behavioral or emotional disturbance, and 3) state a goal related to improved child emotional functioning (eg, self-esteem and happiness). ${ }^{33}$ Among parents of untreated children, two-thirds did not perceive a need for treatment, and $45 \%$ had negative expectations for treatment. ${ }^{33}$ Another qualitative study identified four treatment trajectories among families: 1) delay to diagnosis, 2) initial nonmedication 
treatment pattern, 3) reluctant receipt of diagnosis, and 4) rapid engagement in medication treatment. ${ }^{34}$ Treatment trajectories are influenced by parent explanatory models, extended networks (eg, family members, friends, religious leaders, school officials, and clinicians), and medical utilization factors. ${ }^{34-36}$ Of note, families whose explanatory model closely parallel the biomedical model for ADHD (either from the time of diagnosis or after reframing) appear more likely to engage and maintain use of medication..$^{34,35,37}$ Parents in the initial nonmedication treatment pattern choose to start with "less or no harm approaches". ${ }^{34}$ Home care approaches utilized by parents range from those consistent with evidencebased psychosocial treatment principles to those based more on popular myths (eg, elimination of sugar from diet). ${ }^{5-7,38-40}$ Many parents of children with ADHD or at risk for ADHD believe that ADHD medications are overprescribed by doctors. ${ }^{41-43}$ Some parents prefer behavior modification and are reluctant to initiate medication. ${ }^{33,35,39,42,44}$ Despite this reluctance, many parents feel like they have exhausted parenting approaches and must resort to trying medication. ${ }^{35,36}$ Parents who seek treatment are often driven by their worries about the consequences of their child's problems if left untreated. . $5,36,39,45$ Inclusion of medication in the treatment plan is also facilitated by parent acceptance of the diagnosis of $\mathrm{ADHD}^{34,35}$ and recognition of their child's functional impairments. ${ }^{34,35}$ Trying medication and/or contrasting time on and off medication helps parents to understand the effects and/or side effects for their child and informs subsequent decisions about continuing medication. ${ }^{35,36,46,47}$ A common barrier to trying a full range of dosages is family resistance to increasing the dosage after seeing improvement in their child's behavior on the initial (eg, lowest) dose. ${ }^{48}$ Parents tend to prefer medications that have a long duration. ${ }^{49}$ Some parents come to view medication as necessary to controlling ADHD symptoms enough so that they can then achieve some limited success with psychosocial techniques. ${ }^{50}$ Parents continue to experience fears and worries related to the potential for long-term side effects, even if their child shows marked improvement. ${ }^{35,36,39,45,51}$ This phenomenon is especially pertinent given ongoing public discussion of the effect of stimulant medications on growth ${ }^{52,53}$ and the possible linkage between sudden cardiac death and the use of ADHD medications. ${ }^{54-58}$

\section{Cultural variations in parent treatment preferences}

Parental beliefs about ADHD help explain cultural variations seen in disparities in the rate of medication initiation. ${ }^{19,59,60}$ Understanding ADHD as a medical illness ${ }^{61-63}$ and accepting medication treatment is more common among well-educated, affluent, and Caucasian families ${ }^{33,41,64}$ and among mothers ${ }^{65}$ rather than fathers. ${ }^{66,67}$ Parents from less affluent or minority ethnic backgrounds may have underlying beliefs that contribute to lower rates of medication utilization for ADHD. Whether these beliefs constitute well-informed preferences is debatable. Qualitative studies have shed some light on these subcultural beliefs. Studies among Latino parents demonstrate a lack of trust and shared understanding about the child's problem ${ }^{34}$ and a preference for treatment options other than medication because they understand medication to be addictive, dulling of cognitive processes, and inappropriate for behavioral problems. ${ }^{68,69}$ African-American parents report 1) distrust of ADHD as a diagnosis and of physicians who are quick to prescribe medication, 2) concern that stimulants will lead to drug abuse later in life, and 3) lack of support for medical treatment from their social networks. ${ }^{37,43,70-74}$ Lack of support from social networks is not surprising given the largely negative beliefs and attitudes held about the use of psychoactive medications in children ${ }^{75}$ and the lower likelihood among minorities of espousing the belief that ADHD is a real disorder. ${ }^{76}$

\section{Child and adolescent treatment preferences}

Child and adolescent treatment preferences are an understudied area. Studies have documented that $22 \%-50 \%$ of children dislike taking medication for ADHD. ${ }^{67,77,78}$ In addition, $40 \%-65 \%$ of children avoid taking their medication. ${ }^{42,78}$ Common avoidance tactics include arguments with parents and/or refusal to take it, throwing it away if no one is watching, pretending to take medication and then throwing it away, or deliberately failing to remind a parent who forgot to give it. ${ }^{78}$ Common reasons for avoidance include dislike of pills, embarrassment/social stigma, side effects, negative effect on self-esteem, interference with activities (eg, sports performance), and concern about addiction. ${ }^{42,44,78,79}$ Children in these studies also reported a lack of perceived need for medication, which may relate to the consistent finding that children with ADHD have unrealistically high self-belief about their skills and competence. ${ }^{80-85}$ In addition, many children do not perceive any benefit from taking medication. ${ }^{44,67,78,86}$ Child and parent appraisal of medication effectiveness disagrees in 25\%-33\% of cases. ${ }^{87}$ Twelve percent of children report that they would discontinue treatment if given the choice ${ }^{67,77}$ Given the pervasive nature of child dislike and avoidance of medication, it is not surprising that oppositional symptoms have been 
associated with poor treatment adherence, ${ }^{88}$ and parents have endorsed child reluctance to take their medication as a major reason for discontinuing treatment. ${ }^{36,42,89}$ Beyond avoiding medication, some children simply forget to take their medication..$^{90,91}$

\section{Treatment preferences change over time}

In early work conducted by Firestone, the major reasons parents gave for stopping medication were that they were not comfortable with the idea of medicating their children or that their children were reluctant to take their medication. ${ }^{89}$ Following the initial titration, side effects, when present, were not cited by parents as an important factor in their decision to discontinue treatment. ${ }^{89}$ In 2005, 16 parents of children with ADHD who had stopped taking medication were asked open-ended questions about the reasons for discontinuation. ${ }^{92}$ The most common reasons offered were side effect experiences $(n=6)$, summer medication break $(\mathrm{n}=3)$, and trying to keep the child off medication to see whether ADHD would remit $(n=2)$. Three qualitative studies further depict parent decision making for their child with ADHD. ${ }^{35,36,45}$ Parents described medication decisions as a complex balancing act, with concerns about past and present experiences of adverse effects weighed against the functional improvements seen at home and at school. In addition, parents also considered an uncertain and unpredictable future, with concerns about possible long-term risks of medication weighed against their goals and expectations for their child's future. In addition, this dilemma does not end after a decision has been made and acted on. Rather, parents continually justified and re-evaluated decisions long after they had been made.

\section{Limitations of qualitative and quantitative research assessing treatment preferences}

Qualitative studies are limited by small, geographically confined samples. Results from these qualitative studies cannot be generalized to all children with ADHD or their parents. However, qualitative research provides important insights into poorly understood phenomena that can subsequently be studied using quantitative methods to better characterize the prevalence of the phenomena and/or test implied hypotheses. ${ }^{93}$ The research conducted by Bussing et a ${ }^{92}$ represents the only prospective longitudinal study, leaving the majority of studies based on cross-sectional data. Both qualitative and quantitative studies reviewed are limited by a greater focus on medication rather than psychosocial treatments. There are plausible explanations for this.
First, medication has long been a more controversial and polarizing topic among parents and the media than psychosocial treatment. As such, it has been a popular topic for research. In addition, medication is widely available, so the decision of whether or not to try medication is faced by nearly every parent of a child diagnosed with ADHD. In contrast, psychosocial treatments, although highly acceptable to parents, vary in availability, cost, and quality. As a result, utilization of psychosocial treatments may be less about parent preference and more about barriers to access in a resource-constrained environment. Moreover, there are more datasets (eg, Medicaid) available to investigate utilization of medication than psychosocial treatments. Unfortunately, the current ADHD treatment preference literature does not adequately account for availability of services when assessing preferences. It is possible that parent preferences might change if evidence-based psychosocial treatments were readily available. It may be that parents might show more preference for psychosocial treatment with greater availability. It is also possible that parents might show less preference with greater availability due to trying psychosocial treatments and finding that they did not fully address impairments.

\section{Summary of qualitative and quantitative research assessing treatment preferences}

After a child is diagnosed with ADHD, a variety of factors influence the initial selection of treatment modalities that are utilized. Initial parent and child preferences are shaped by their beliefs about the nature of the child's problems and by information (and misinformation) received from a variety of sources, including social networks, the media, and health care providers. Subsequently, preferences become further informed by personal experience with various treatment modalities. Over time, treatment plans are revisited and revised (ie, treatment modalities are added and subtracted, and/or current approaches are modified) as families work with their health care team to establish a treatment plan that helps their child achieve goals while minimizing harms and costs. This process of optimizing care is similar to the family/self-management processes described for other chronic conditions..$^{94}$ Even when treatment plans are congruent with well-informed patient/parent preferences and values, there can be barriers to implementation and/or persistence with treatment. Children can forget to take medication, and parents might forget to give medication. Families can struggle with the out-of-pocket costs for medication and/or psychosocial treatments. Access to high-quality psychosocial treatments may be limited. When available, 
there are additional barriers to learning and implementing psychosocial treatment strategies.

\section{Discussion}

There are multiple treatments for ADHD that are effective. Because the treatment options differ on benefits and risks/ costs, the best choice is preference sensitive and depends on how an informed patient/parent values the tradeoffs between options. ${ }^{23}$ There are many publications examining variation in treatment utilization among children with ADHD. Most have focused on medication, as this is the most widely available treatment modality, and there are multiple sources of data available for analysis. However, these datasets are devoid of information about patient/parent preferences and knowledge regarding the likelihood of treatment outcomes (eg, benefits and risks/costs). Therefore, studies have not been able to distinguish between "unwarranted" and "warranted" sources of variation. For example, the nearly two-fold variation in medication use between children diagnosed with ADHD in Nebraska and California ${ }^{19}$ would be unwarranted if not consistent with the distribution of informed patient/ parent treatment preferences. ${ }^{23}$ Studies are needed to better characterize the amount of unwarranted variation in ADHD treatment patterns. Certainly, strategies are needed to ensure that 1) patients/parents are well informed about likely benefits and risks/costs of treatment and 2) patient/parent goals, preferences, and values are elicited and discussed. Shared decision making is one process to accomplish these objectives. Using shared decision-making tools, practitioners communicate information on the options, outcomes, probabilities, and scientific uncertainties, and patients/parents communicate the personal value they place on the benefits versus harms so that agreement on the best strategy can be reached. ${ }^{95}$ Studies are needed to test shared decision-making interventions among parents of children with ADHD. In addition, studies are needed to determine the extent to which psychosocial treatments are excluded from the treatment plan due to family preference rather than poor access to services or physicians underestimating parent preferences for this modality.

As a chronic condition, it is natural for patient/parent goals, preferences, and values to evolve over time. Treatment plans must be revised to reflect these changes and progress made toward goals. It is not clear how often patient/parents and physicians explicitly set and/or revise goals for treatment, although there is some evidence that goals are infrequently documented in the medical record. ${ }^{96,97}$ In addition, it is not clear whether goals set are specific, measurable, attainable, relevant, and time bound. These dimensions are important in increasing the chance that goal setting leads to improvement. ${ }^{98}$ Likewise, it is not clear how often patient/parent preferences and values are elicited and discussed. In one study, only $44 \%$ of parents of a child with psychosocial problems reported that their child's doctor always asked about his/her ideas and opinions when planning care for their child. ${ }^{99}$ Measuring meaningful outcomes over time is essential in order to help appraise progress toward goals. ${ }^{3}$ The American Academy of Pediatrics recommends a wide range of methods to obtain information about progress on target symptoms, including office interviews, telephone conversations, teacher narratives, periodic behavior report cards, and behavioral ratings. ${ }^{3}$ The behavioral ratings commonly collected in practice (eg, Connors and Vanderbilt Rating Scales) focus on symptoms and impairment. Tracking symptoms may be a good proxy for other functional outcomes given the strong negative correlation observed between ADHD symptoms and health-related quality of life (ie, lower symptoms related to better quality of life). ${ }^{100-105}$ However, there is evidence that impairment often persists despite a reduction in ADHD symptoms. ${ }^{106}$ Therefore, collection of impairment and potentially other measures may add value as adaptive functioning outcomes appear important to patients/parents. ${ }^{107,108}$ There is a significant dropoff in the number of parent and teacher behavioral ratings that are obtained by physicians over time. ${ }^{106}$ It is not clear to what extent this phenomenon is based on 1) a conscious decision to discontinue monitoring based on child symptom remission documented on a previous checklist or 2) challenges for parents and physicians to sustain engagement in ongoing monitoring activities in the absence of an ADHD-precipitated child/family crisis. Regardless, the absence of such data makes it difficult to understand the changes in treatment utilization that occur over time. In the absence of symptom remission and/or goal attainment, what factors contribute to treatment discontinuation? Investigators from the MTA recently identified the need to address this gap in the literature as they stated: "It is clear that additional studies are needed to characterize who starts and who stops treatment with medication, and for what reasons, during the course of long-term treatment" ${ }^{109}$

\section{Conclusions}

Treatment planning for children with ADHD is a dynamic process. Ideally, this process includes consideration of scientific evidence about the efficacy of treatments as well as patient/parent goals, preferences, and values. There are challenges to ensure that patient/parent preferences are consistently well informed, elicited, and discussed in the treatment 
planning process. Interventions are needed to promote such interactions. Such research is a necessary step that will enable more meaningful conclusions to be drawn about the appropriateness of treatment utilization rates in a given population.

\section{Acknowledgments}

The authors are supported by Award Numbers K23MH083027 (Dr Brinkman) and K24MH064478 (Dr Epstein) from the National Institute of Mental Health. Dr Epstein also receives grant funding from Eli Lilly and Company. The content is solely the responsibility of the authors and does not necessarily represent the official views of the National Institute of Mental Health or the National Institutes of Health.

\section{Disclosure}

The authors report no conflicts of interest in this work.

\section{References}

1. Froehlich TE, Lanphear BP, Epstein JN, Barbaresi WJ, Katusic SK, Kahn RS. Prevalence, recognition, and treatment of attention-deficit/ hyperactivity disorder in a national sample of US children. Arch Pediatr Adolesc Med. 2007;161(9):857-864.

2. The MTA Cooperative Group. A 14-month randomized clinical trial of treatment strategies for attention-deficit/hyperactivity disorder. Arch Gen Psychiatry. 1999;56(12):1073-1086.

3. American Academy of Pediatrics. Subcommittee on Attention-Deficit/ Hyperactivity Disorder and Committee on Quality Improvement. Clinical practice guideline: treatment of the school-aged child with attention-deficit/ hyperactivity disorder. Pediatrics. 2001;108(4):1033-1044.

4. Pliszka S. AACAP Work Group on Quality Issues. Practice parameter for the assessment and treatment of children and adolescents with attention-deficit/hyperactivity disorder. $J$ Am Acad Child Adolesc Psychiatry. 2007;46(7):894-921.

5. Chan E, Rappaport LA, Kemper KJ. Complementary and alternative therapies in childhood attention and hyperactivity problems. $J$ Dev Behav Pediatr. 2003;24(1):4-8.

6. Johnston C, Seipp C, Hommersen P, Hoza B, Fine S. Treatment choices and experiences in attention deficit and hyperactivity disorder: relations to parents' beliefs and attributions. Child Care Health Dev. 2005;31(6):669-677.

7. Concannon PE, Tang YP. Management of attention deficit hyperactivity disorder: a parental perspective. J Paediatr Child Health. 2005;41(12): 625-630.

8. Rucklidge JJ, Johnstone J, Kaplan BJ. Nutrient supplementation approaches in the treatment of ADHD. Expert Rev Neurother. 2009; 9(4):461-476.

9. Swanson JM, Kraemer HC, Hinshaw SP, et al. Clinical relevance of the primary findings of the MTA: success rates based on severity of ADHD and ODD symptoms at the end of treatment. $\mathrm{Am}$ Acad Child Adolesc Psychiatry. 2001;40(2):168-179.

10. Pelham WE Jr, Fabiano GA. Evidence-based psychosocial treatments for attention-deficit/hyperactivity disorder. J Clin Child Adolesc Psychol. 2008;37(1):184-214.

11. Barkley RA, Shelton TL, Crosswait C, et al. Multi-method psychoeducational intervention for preschool children with disruptive behavior: preliminary results at post-treatment. $J$ Child Psychol Psychiatry. 2000;41(3):319-332.

12. Bussing R, Zima BT, Belin TR. Variations in ADHD treatment among special education students. $J$ Am Acad Child Adolesc Psychiatry. 1998;37(9):968-976.
13. The MTA Cooperative Group. Moderators and mediators of treatment response for children with attention-deficit/hyperactivity disorder: the Multimodal Treatment Study of children with attention-deficit/ hyperactivity disorder. Arch Gen Psychiatry. 1999;56(12):1088-1096.

14. Greenhill LL, Swanson JM, Vitiello B, et al. Impairment and deportment responses to different methylphenidate doses in children with ADHD: the MTA titration trial. J Am Acad Child Adolesc Psychiatry. 2001;40(2):180-187.

15. Vitiello B, Severe JB, Greenhill LL, et al. Methylphenidate dosage for children with ADHD over time under controlled conditions: lessons from the MTA. J Am Acad Child Adolesc Psychiatry. 2001;40(2):88-196.

16. Epstein JN, Rabiner D, Johnson DE, et al. Improving attention-deficit/ hyperactivity disorder treatment outcomes through use of a collaborative consultation treatment service by community-based pediatricians: a cluster randomized trial. Arch Pediatr Adolesc Med. 2007;161(9): 835-840.

17. Pappadopulos E, Jensen PS, Chait AR, et al. Medication adherence in the MTA: saliva methylphenidate samples versus parent report and mediating effect of concomitant behavioral treatment. J Am Acad Child Adolesc Psychiatry. 2009;48(5):501-510.

18. Hudson JL, Miller GE, Kirby JB. Explaining racial and ethnic differences in children's use of stimulant medications. Med Care. 2007; 45(11):1068-1075.

19. Centers for Disease Control and Prevention (CDC). Mental health in the United States. Prevalence of diagnosis and medication treatment for attention-deficit/hyperactivity disorder - United States, 2003. MMWR Morb Mortal Wkly Rep. 2005;54(34):842-847.

20. Marcus SC, Wan GJ, Kemner JE, Olfson M. Continuity of methylphenidate treatment for attention-deficit/hyperactivity disorder. Arch Pediatr Adolesc Med. 2005;159(6):572-578.

21. Sanchez RJ, Crismon ML, Barner JC, Bettinger T, Wilson JP. Assessment of adherence measures with different stimulants among children and adolescents. Pharmacotherapy. 2005;25(7):909-917.

22. Bokhari FAS, Heiland F, Levine P, Ray GT. Risk factors for discontinuing drug therapy among children with ADHD. Health Serv Outcomes Res Methodol. 2008;8(3):134-158.

23. Wennberg JE, Fisher ES, Skinner JS. Geography and the debate over Medicare reform. Health Aff (Millwood). 2002;Suppl Web Exclusives: W96-W114.

24. Kazdin AE. Acceptability of alternative treatments for deviant child behavior. J Appl Behav Anal. 1980;13(2):259-273.

25. Liu C, Robin AL, Brenner S, Eastman J. Social acceptability of methylphenidate and behavior modification for treating attention deficit hyperactivity disorder. Pediatrics. 1991;88(3):560-565.

26. Gage JD, Wilson LJ. Acceptability of attention-deficit/hyperactivity disorder interventions: a comparison of parents. J Atten Disord. 2000; 4(3):174-182.

27. Johnston C, Fine S. Methods of evaluating methylphenidate in children with attention deficit hyperactivity disorder: acceptability, satisfaction, and compliance. J Pediatr Psychol. 1993;18(6):717-730.

28. Johnston C, Hommersen P, Seipp C. Acceptability of behavioral and pharmacological treatments for attention-deficit/hyperactivity disorder: relations to child and parent characteristics. Behav Ther. 2008;39(1): $22-32$.

29. Krain AL, Kendall PC, Power TJ. The role of treatment acceptability in the initiation of treatment for ADHD. J Atten Disord. 2005;9(2): 425-434.

30. Rostain AL, Power TJ, Atkins MS. Assessing parents' willingness to pursue treatment for children with attention-deficit hyperactivity disorder. J Am Acad Child Adolesc Psychiatry. 1993;32(1):175-181.

31. Corkum P, Rimer P, Schachar R. Parental knowledge of attention-deficit hyperactivity disorder and opinions of treatment options: impact on enrollment and adherence to a 12-month treatment trial. Can J Psychiatry. 1999;44(10):1043-1048.

32. Bennett DS, Power TJ, Rostain AL, Carr DE. Parent acceptability and feasibility of ADHD interventions: assessment, correlates, and predictive validity. J Pediatr Psychol. 1996;21(5):643-657. 
33. Bussing R, Gary FA, Mills TL, Garvan CW. Parental explanatory models of ADHD: gender and cultural variations. Soc Psychiatry Psychiatr Epidemiol. 2003;38(10):563-575.

34. Leslie LK, Plemmons D, Monn AR, Palinkas LA. Investigating ADHD treatment trajectories: listening to families' stories about medication use. J Dev Behav Pediatr. 2007;28(3):179-188.

35. Brinkman WB, Sherman SN, Zmitrovich AR, et al. Parental angst making and revisiting decisions about treatment of attention-deficit/ hyperactivity disorder. Pediatrics. 2009;124(2):580-589.

36. Charach A, Skyba A, Cook L, Antle BJ. Using stimulant medication for children with ADHD: what do parents say? A brief report. $J$ Can Acad Child Adolesc Psychiatry. 2006;15(2):75-83.

37. DosReis S, Mychailyszyn MP, Evans-Lacko SE, Beltran A, Riley AW, Myers MA. The meaning of attention-deficit/hyperactivity disorder medication and parents' initiation and continuity of treatment for their child. J Child Adolesc Psychopharmacol. 2009;19(4): 377-383.

38. Wolraich ML, Wilson DB, White JW. The effect of sugar on behavior or cognition in children. A meta-analysis. JAMA. 1995;274(20): $1617-1621$.

39. Bussing R, Gary FA. Practice guidelines and parental ADHD treatment evaluations: friends or foes? Harv Rev Psychiatry. 2001;9(5): 223-233.

40. Bussing R, Zima BT, Gary FA, Garvan CW. Use of complementary and alternative medicine for symptoms of attention-deficit hyperactivity disorder. Psychiatr Serv. 2002;53(9):1096-1102.

41. Bussing R, Schoenberg NE, Perwien AR. Knowledge and information about ADHD: evidence of cultural differences among African-American and white parents. Soc Sci Med. 1998;46(7):919-928.

42. DosReis S, Zito JM, Safer DJ, Soeken KL, Mitchell JW Jr, Ellwood LC. Parental perceptions and satisfaction with stimulant medication for attention-deficit hyperactivity disorder. J Dev Behav Pediatr. 2003; 24(3):155-162.

43. DosReis S, Butz A, Lipkin PH, Anixt JS, Weiner CL, Chernoff R. Attitudes about stimulant medication for attention-deficit/hyperactivity disorder among African American families in an inner city community. J Behav Health Serv Res. 2006;33(4):423-430.

44. Henker B, Whalen CK. The many messages of medication: hyperactive children's perceptions and attributions. In: Salzinger S, Antrobus J, Glick J, editors. The Ecosystem of the "Sick" Child. New York (NY): Academic Press, Inc; 1980.

45. Hansen DL, Hansen EH. Caught in a balancing act: parents' dilemmas regarding their ADHD child's treatment with stimulant medication. Qual Health Res. 2006;16(9):1267-1285.

46. Nikles CJ, Clavarino AM, Del Mar CB. Using n-of-1 trials as a clinical tool to improve prescribing. Br J Gen Pract. 2005;55(512): 175-180.

47. Kent MA, Camfield CS, Camfield PR. Double-blind methylphenidate trials: practical, useful, and highly endorsed by families. Arch Pediatr Adolesc Med. 1999;153(12):1292-1296.

48. Pliszka SR, Lopez M, Crismon ML, et al. A feasibility study of the children's medication algorithm project (CMAP) algorithm for the treatment of ADHD. J Am Acad Child Adolesc Psychiatry. 2003;42(3): 279-287.

49. Mühlbacher AC, Rudolph I, Lincke HJ, Nübling M. Preferences for treatment of attention-deficit/hyperactivity disorder (ADHD): a discrete choice experiment. BMC Health Serv Res. 2009;9:149.

50. Bull C, Whelan T. Parental schemata in the management of children with attention deficit-hyperactivity disorder. Qual Health Res. 2006;16(5): 664-678.

51. Berger I, Dor T, Nevo Y, Goldzweig G. Attitudes toward attention-deficit hyperactivity disorder (ADHD) treatment: parents' and children's perspectives. J Child Neurol. 2008;23(9):1036-1042.

52. The MTA Cooperative Group. National Institute of Mental Health Multimodal Treatment Study of ADHD follow-up: changes in effectiveness and growth after the end of treatment. Pediatrics. 2004; 113(4):762-769.
53. Swanson JM, Hinshaw SP, Arnold LE, et al. Secondary evaluations of MTA 36-month outcomes: propensity score and growth mixture model analyses. J Am Acad Child Adolesc Psychiatry. 2007;46(8):1003-1014.

54. Nissen SE. ADHD drugs and cardiovascular risk. NEngl J Med. 2006; 354(14):1445-1448.

55. Perrin JM, Friedman RA, Knilans TK. Black Box Working Group. Cardiovascular monitoring and stimulant drugs for attention-deficit/ hyperactivity disorder. Pediatrics. 2008;122(2):451-453.

56. Vetter VL, Elia J, Erickson C, et al. Cardiovascular monitoring of children and adolescents with heart disease receiving medications for attention deficit/hyperactivity disorder [corrected]: a scientific statement from the American Heart Association Council on Cardiovascular Disease in the Young Congenital Cardiac Defects Committee and the Council on Cardiovascular Nursing. Circulation. 2008;117(18):2407-2423.

57. Wilens TE, Prince JB, Spencer TJ, Biederman J. Stimulants and sudden death: what is a physician to do? Pediatrics. 2006;118(3): 1215-1219.

58. Biederman J, Spencer TJ, Wilens TE, Prince JB, Faraone SV. Treatment of ADHD with stimulant medications: response to Nissen perspective in the New England Journal of Medicine. J Am Acad Child Adolesc Psychiatry. 2006;45(10):1147-1150.

59. Olfson M, Gameroff MJ, Marcus SC, Jensen PS. National trends in the treatment of attention deficit hyperactivity disorder. Am J Psychiatry. 2003;160(6):1071-1077.

60. Stevens J, Harman JS, Kelleher KJ. Race/ethnicity and insurance status as factors associated with ADHD treatment patterns. J Child Adolesc Psychopharmacol. 2005;15(1):8-96.

61. Harborne A, Wolpert M, Clare L. Making sense of ADHD: a battle for understanding? Parents' views of their children being diagnosed with ADHD. Clin Child Psychol Psychiatry. 2004;9(3):327-339.

62. Klasen H. A name, what's in a name? The medicalization of hyperactivity, revisited. Harv Rev Psychiatry. 2000;7(6):334-344.

63. Malacrida C. Medicalization, ambivalence and social control: mothers' descriptions of educators and ADD/ADHD. Health (London). 2004; 8(1):61-80.

64. Bussing R, Zima BT, Belin TR. Differential access to care for children with ADHD in special education programs. Psychiatr Serv. 1998;49(9): 1226-1229.

65. Singh I. Doing their jobs: mothering with Ritalin in a culture of motherblame. Soc Sci Med. 2004;59(6):193-1205.

66. Singh I. Boys will be boys: fathers' perspectives on ADHD symptoms, diagnosis, and drug treatment. Harv Rev Psychiatry. 2003;11(6): 308-316.

67. Baxley GB, Turner PF, Greenwold WE. Hyperactive children's knowledge and attitudes concerning drug treatment. J Pediatr Psychol. 1978;3(4):172-176.

68. Arcia E, Fernández MC, Jáquez M. Latina mothers' stances on stimulant medication: complexity, conflict, and compromise. J Dev Behav Pediatr. 2004;25(5):311-317.

69. Perry CE, Hatton D, Kendall J. Latino parents' accounts of attention deficit hyperactivity disorder. $J$ Transcult Nurs. 2005;16(4): 312-321.

70. DosReis S, Mychailyszyn MP, Myers M, Riley AW. Coming to terms with ADHD: how urban African-American families come to seek care for their children. Psychiatr Serv. 2007;58(5):636-641.

71. Olaniyan $\mathrm{O}$, dosReis S, Garriett V, et al. Community perspectives of childhood behavioral problems and ADHD among African American parents. Ambul Pediatr. 2007;7(3):226-231.

72. Guevara JP, Feudtner C, Romer D, et al. Fragmented care for innercity minority children with attention-deficit/hyperactivity disorder. Pediatrics. 2005;116(4):e512-e517.

73. Davidson JC, Ford DY. Perceptions of attention deficit hyperactivity disorder in one African American community. J Negro Educ. 2001;70(4): 264-274.

74. DosReis S, Barksdale CL, Sherman A, Maloney K, Charach A. Stigmatizing experiences of parents of children with a new diagnosis of ADHD. Psychiatr Serv. 2010;61(8):811-816. 
75. Pescosolido BA, Perry BL, Martin JK, McLeod JD, Jensen PS. Stigmatizing attitudes and beliefs about treatment and psychiatric medications for children with mental illness. Psychiatr Serv. 2007;58(5): 613-618.

76. McLeod JD, Fettes DL, Jensen PS, Pescosolido BA, Martin JK. Public knowledge, beliefs, and treatment preferences concerning attentiondeficit hyperactivity disorder. Psychiatr Serv. 2007;58(5):626-631.

77. Bowen J, Fenton T, Rappaport L. Stimulant medication and attention deficit-hyperactivity disorder. The child's perspective. Am J Dis Child. 1991;145(3):291-295.

78. Sleator EK, Ullmann RK, von Neumann A. How do hyperactive children feel about taking stimulants and will they tell the doctor? Clin Pediatr (Phila). 1982;21(8):474-479.

79. Kendall J, Hatton D, Beckett A, Leo M. Children's accounts of attentiondeficit/hyperactivity disorder. ANS Adv Nurs Sci. 2003;26(2):114-130.

80. Hoza B, Gerdes AC, Hinshaw SP, et al. Self-perceptions of competence in children with ADHD and comparison children. $J$ Consult Clin Psychol. 2004;72(3):382-391.

81. Hoza B, Owens JS, Pelham WE, et al. Parent cognitions as predictors of child treatment response in attention-deficit/hyperactivity disorder. J Abnorm Child Psychol. 2000;28(6):569-583.

82. Hoza B, Pelham WE Jr, Dobbs J, Owens JS, Pillow DR. Do boys with attention-deficit/hyperactivity disorder have positive illusory self-concepts? J Abnorm Psychol. 2002;111(2):268-278.

83. Hoza B, Pelham WE, Milich R, Pillow D, McBride K. The selfperceptions and attributions of attention deficit hyperactivity disordered and nonreferred boys. J Abnorm Child Psychol. 1993;21(3):271-286.

84. Owens JS, Goldfine ME, Evangelista NM, Hoza B, Kaiser NM. A critical review of self-perceptions and the positive illusory bias in children with ADHD. Clin Child Fam Psychol Rev. 2007;10(4):335-351.

85. Owens JS, Hoza B. The role of inattention and hyperactivity/impulsivity in the positive illusory bias. J Consult Clin Psychol. 2003;71(4):680-691.

86. Pelham WE, Hoza B, Pillow DR, et al. Effects of methylphenidate and expectancy on children with ADHD: behavior, academic performance, and attributions in a summer treatment program and regular classroom settings. J Consult Clin Psychol. 2002;70(2):320-335.

87. Efron D, Jarman FC, Barker MJ. Child and parent perceptions of stimulant medication treatment in attention deficit hyperactivity disorder. J Paediatr Child Health. 1998;34(3):288-292.

88. Thiruchelvam D, Charach A, Schachar RJ. Moderators and mediators of long-term adherence to stimulant treatment in children with ADHD. J Am Acad Child Adolesc Psychiatry. 2001;40(8):922-928.

89. Firestone P. Factors associated with children's adherence to stimulant medication. Am J Orthopsychiatry. 1982;52(3):447-457.

90. Meaux JB, Hester C, Smith B, Shoptaw A. Stimulant medications: a trade-off? The lived experience of adolescents with ADHD. J Spec Pediatr Nurs. 2006;11(4):214-226.

91. Knipp DK. Teens' perceptions about attention deficit/hyperactivity disorder and medications. $J$ Sch Nurs. 2006;22(2):120-125.

92. Bussing R, Zima BT, Mason D, Hou W, Garvan CW, Forness S. Use and persistence of pharmacotherapy for elementary school students with attention-deficit/hyperactivity disorder. $J$ Child Adolesc Psychopharmacol. 2005;15(1):78-87.

93. Giacomini MK, Cook DJ. Users' guides to the medical literature: XXIII. Qualitative research in health care A. Are the results of the study valid? Evidence-Based Medicine Working Group. JAMA. 2000;284(3): $357-362$.

Patient Preference and Adherence

\section{Publish your work in this journal}

Patient Preference and Adherence is an international, peer-reviewed, open access journal focusing on the growing importance of patient preference and adherence throughout the therapeutic continuum. Patient satisfaction, acceptability, quality of life, compliance, persistence and their role in developing new therapeutic modalities and compounds to
94. Wagner EH, Austin BT, von Korff M. Organizing care for patients with chronic illness. Milbank Q. 1996;74(4):511-544.

95. O'Connor AM, Llewellyn-Thomas HA, Flood AB. Modifying unwarranted variations in health care: shared decision making using patient decision aids. Health Aff (Millwood). 2004;Suppl Web Exclusives:VAR63-VAR72.

96. Epstein JN, Langberg JM, Lichtenstein PK, Mainwaring BA, Luzader CP, Stark LJ. Community-wide intervention to improve the attention-deficit/hyperactivity disorder assessment and treatment practices of community physicians. Pediatrics. 2008;122(1):19-27.

97. Homer CJ, Horvitz L, Heinrich P, Forbes P, Lesneski C, Phillips J. Improving care for children with attention deficit hyperactivity disorder: assessing the impact of self-assessment and targeted training on practice performance. Ambul Pediatr. 2004;4(5):436-441.

98. Doran GT. There's a S.M.A.R.T. way to write management's goals and objectives. Manage Rev. 1981;70(11):35-36.

99. Hart CN, Kelleher KJ, Drotar D, Scholle SH. Parent-provider communication and parental satisfaction with care of children with psychosocial problems. Patient Educ Couns. 2007;68(2):179-185.

100. Klassen AF, Miller A, Fine S. Health-related quality of life in children and adolescents who have a diagnosis of attention-deficit/hyperactivity disorder. Pediatrics. 2004;114(5):e541-e547.

101. Perwien AR, Faries DE, Kratochvil CJ, Sumner CR, Kelsey DK, Allen AJ. Improvement in health-related quality of life in children with ADHD: an analysis of placebo controlled studies of atomoxetine. J Dev Behav Pediatr. 2004;25(4):264-271.

102. Perwien AR, Kratochvil CJ, Faries DE, Vaughan BS, Spencer T, Brown RT. Atomoxetine treatment in children and adolescents with attention-deficit hyperactivity disorder: what are the long-term healthrelated quality-of-life outcomes? J Child Adolesc Psychopharmacol. 2006;16(6):713-724.

103. Rentz AM, Matza LS, Secnik K, Swensen A, Revicki DA. Psychometric validation of the child health questionnaire (CHQ) in a sample of children and adolescents with attention-deficit/hyperactivity disorder. Qual Life Res. 2005;14(3):719-734.

104. Sawyer MG, Whaites L, Rey JM, Hazell PL, Graetz BW, Baghurst P. Health-related quality of life of children and adolescents with mental disorders. J Am Acad Child Adolesc Psychiatry. 2002;41(5): 530-537.

105. Varni JW, Burwinkle TM. The PedsQL as a patient-reported outcome in children and adolescents with attention-deficit/hyperactivity disorder: a population-based study. Health Qual Life Outcomes. 2006;4:26.

106. Epstein JN, Langberg JM, Lichtenstein PK, et al. Attention-deficit/ hyperactivity disorder outcomes for children treated in communitybased pediatric settings. Arch Pediatr Adolesc Med. 2010;164(2): $160-165$.

107. Saylor KE, Buermeyer CM, Spencer TJ, Barkley RA. Adaptive changes related to medication treatment of ADHD: listening to parents of children in clinical trials of a novel nonstimulant medication. J Clin Psychiatry. 2002;63 Suppl 12:23-28.

108. Cunningham CE. A family-centered approach to planning and measuring the outcome of interventions for children with attention-deficit/ hyperactivity disorder. Ambul Pediatr. 2007;7(1 Suppl):60-72.

109. Swanson J, Arnold LE, Kraemer H, et al. Evidence, interpretation, and qualification from multiple reports of long-term outcomes in the Multimodal Treatment Study of children with ADHD (MTA): Part II: supporting details. J Atten Disord. 2008;12(1):15-43.

\section{Dovepress}

optimize clinical outcomes for existing disease states are major areas of interest. This journal has been accepted for indexing on PubMed Central. The manuscript management system is completely online and includes a very quick and fair peer-review system. Visit http://www.dovepress. com/testimonials.php to read real quotes from published authors. 